\title{
DEVELOPMENT OF AN INNOVATIVE APPROACH FOR COMPLEX, CAUSALLY DETERMINED FAILURE CHAINS
}

\author{
Ovidiu Bielefeld, Hendrik Dransfeld, Nadine Schlüter, Petra Winzer \\ University of Wuppertal, Research Group "Product Safety and Quality Engineering", Germany \\ Corresponding author: \\ Ovidiu Bielefeld University of Wuppertal \\ Research Group "Product Safety and Quality Engineering" \\ Gaußstr. 20, 42119 Wuppertal, Germany \\ phone: 0202 / 439-3210 \\ e-mail: bielefeld@uni-wuppertal.de
}

Received: 25 December 2016

Accepted: 2 April 2017

\begin{abstract}
A high number of examples in today's global industry prove that it is difficult to ensure a certain level of quality. One possible reason is the increasing complexity of modern mechatronic product systems. Interface problems due to several involved science disciplines and the lack of understanding subsystems, which are delivered by different suppliers, make it difficult to identify critical components and specifications of elements. Furthermore, it is even harder to estimate the effects of elements because of their unknown dependencies and relations. Therefore it becomes more and more improbable to develop a safe, sustainable and high quality product right from the beginning.

In order to understand failures in complex system structures today's engineering industries need a generic approach that increases the understanding of systems, identifies critical components and considers the different levels of a system. It shall examine failures that cause system errors but also failures that limit system functions. Thus, it is necessary to model and simulate the causally failure chains and analyse over several system levels and elements with their dependencies. This leads to a better understanding of the whole picture of cause and effect.

This research paper points out which requirements this new model-based approach has to fulfill and how it is possible to link quality and reliability methods to achieve an overall understanding and analysis of a complex system to assure high quality and sustainability.
\end{abstract}

KEYWORDS

model-based failure analysis, reliability, quality, safety.

\section{Introduction}

The increasing complexity of modern products is the cause of many quality problems and deficit concerning technical reliability [1-3]. An example for this is the vast number of recalls in the automotive industry which should be considered [4]. Apparently, many challenges in the industry are not solved yet, due to the high level of their complexity. Complexity in this context is meant as a variety of interacting elements of a product. The relationships between the elements are not only different, but also dynamic [5, 6]. Dominating the product complexity is already a challenge due to interaction of different specialist disciplines. It is becoming more complicated and each has its own linguistic habits, models and approaches [7].
To handle complexity of systems and the resulting quality problems and deficits concerning technical reliability, first it is necessary to understand complexity [3] and this can only be understood on basis of a holistic and transdisciplinary system model [8]. For that reason, it is necessary to develop a new integral methodology, which increases the understanding of the system and the system thinking by using a coherent image of the system and creates a common understanding within a multidisciplinary team $[8,9]$. The new methodology must contain a system model that helps to identify and isolate complex failure chains in order to reduce failure problems and deficits regarding quality, safety and technical reliability. Such failure chains are complex, because they show cause and effect in a system, even if different level of the system or different kinds of element types 
are involved and interact with each other. Therefore the new approach for complex causally determined failure chains has to handle complex logical causeeffect-chains along several system level and types of elements.

The following section explains which requirements must be fulfilled by the new approach for complex causally determined failure chains. For this purpose, scientific and technical literature has been analysed in order to compare current quality and reliability methods with requirements for a new approach. Based on the scientific gap the innovative approach has been developed.

At first the new approach will be described theoretically in the third section of this paper. After this, the approach will be validated, give a concrete example and will be linked with one of the most important failure analysis methods in the scientific and technical literature and industrial applications (section four). Finally, it will be evaluated in the conclusion, when the requirements of the new approach have been fulfilled.

\section{Requirements for a new approach for complex causally determined failure chains}

As mentioned above, an approach for complex causally determined failure chains is required. In addition, it is necessary to concretise, which requirements this new approach has to fulfill. Therefore, the best-known failure analysis methods from the literature were analysed in order to find out, if one of these methods fulfill the requirements related to a modelbased integral approach. Furthermore, for a better understanding of these methods and of causally determined failure chains the term "failure" must be clarified.

\section{Definitions of the failure}

Several definitions can be found in the relevant literature. While in the ISO 9000 failure is defined as a "non-fulfilment of a requirement" [10], the ISO 26262 discribes failure as breakdown of an element in a system regarding to fulfil its appropriate function [11]. Simultaneously the definition of the ISO 26262, Pahl/Beitz [12] describes, how to create a FTA based on negated functions. Other sources describe a failure as component failure $[13,14]$. For a systematic analysis of failure chains, it is necessary to use an adequate definition of "failure" and a procedure to standardize this term. Therefore, the definition that will be used here, is from Pahl/Beitz [12].
For example, a function of a data medium is defined as "save data"; the potential failure could be described in defining it by the negated function of the data medium to "not save data". The same procedure can also be used for other functions, which are involved in a causally determined failure chains.

\section{Analysis of methods}

A high brandwidth of failure analysis methods, which are applied to increase the quality and the reliability of the products, already exist. In the scientific and technical literature, these methods are divided into deductive and inductive methods [15, 16]. The deductive methods start from a failure and end by the cause of a failure, while the inductive methods focus on the effects of a failure [11]. These established deductive methods are for example the Failure Tree Analysis (FTA), Ishikawa Diagram and the Failure Mode Effects Analysis (FMEA). Inductive methods include the Event Tree Analysis (ETA) and Markov [11].

To determine and analyze complex causality failure chains, the length of a chain of causality should not be limited by methods like FMEA [17]. The FMEA form sheet usually includes one column for a potential type of failure, one for a potential cause of failures and one for the effects of a failure [18, 19]. Due to a large number of causes and effects that can be chained together, it is not sufficient just to understand the complexity of failure chains [11, 20-22].

The quantitative FTA is suitable for the analysis of the component failure and causes by using the binary logic a systems breakdown $[13,23]$. The components are either functional or nonfunctional. A systems breakdown is not always caused by the failure of a physical component. Moreover the increasing number of integration of functions should definitely be considered [24]. For an impact assessment of the overall system there is a great tendency to predict the functions, which are not performed correctly. But not always one component has only one function, the implementation from one function can be executed by more than a component or more than one function may be assigned to a component [25, 26]. Approaches like, for example, the extension from FTA including the functional dependency $[27,28]$ show that reconsideration is necessary for the benefit of the functional orientation. Liggesmeyer [20] considers for applying FTA and FMEA by his modularized model the system and system environment, though the analysis to focus only on components and functions that are not taken into account. The Bayes Network and artificial neural networks focus on the data statistical analysis [29]. The problem with this is that large 
quantities of necessary data are not available in the development phase of new products. For this reason, the application of these methods is not recommended in the development of new products [17].

In summary, it can be said that none of those analyzed methods fulfill the requirements related to a model-based integral method, which can make it possible to analyze failure chains in a system if different levels of the system or different kind of element types are involved [17]. The results are summarized in Table 1.

Table 1

Characteristics of reliability methods based on [15, 29, 30].

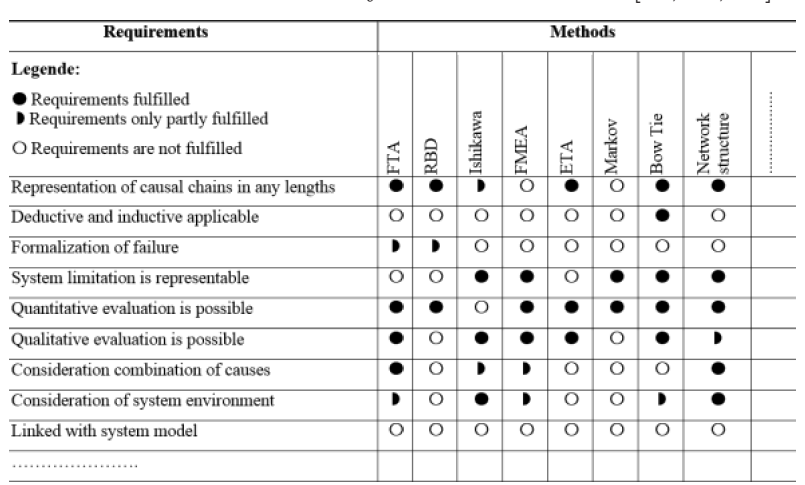

\section{Requirements regarding the system model}

Although there is a high brandwidth of methods for failure analysis to increase the quality and the reliability of the products, there is no integral approach. No system model is able to show a system with a common system awareness and the basic principles. That is why for the generation and analysis of complex failure chains, a system model is necessary $[17,[31]$.

To solve the issues that have been mentioned above, the following requirements have to be fulfilled by the innovative approach for complex causally determined failure chains:

- The The failure analysis is based on an integral system model,

- with the help of failure chains, it must be possible to show cause and effect in a system, even if different levels of the system or different kinds of element types are involved and

- It has to be possible to link the system model with failure analysis methods.

To fulfill the requirements above, a standardized and holistic system model with open interfaces and a consistent image of the system is nessesary in order to enable a common understanding and effective communication in multidisciplinary teams. Furthermore, it must be possible to generate failure chains from the system model. Based on the results of lit- erature research and project experience by the Research Group "Product Safety and Quality Engineering" the model that has been chosen is the Demand Compliant Design (DeCoDe) (see also [32]). DeCoDe is the basis for the new approach, which is explained in more detail in the following sections.

\section{Theoretical description of a new approach for complex causally determined failure chains}

For the analysis of complex causally determined failure chains, a standardized system model is necessary, so that causally failure chains could be imaged and analyzed over several system levels and elements with their dependencies. Hence, the generation of a system model is the first step and the starting point by the development of approach. Based on the system model causally determined failure chains will be isolated and analyzed. The overall develop of the approach is comprised the following five steps:

1. Definition of the problem and the system.

2. Definition of the system boundary.

3. Definition of the purpose reagarding modelling the system.

4. Isolation and analysis of complex failure chains that have been generated from the system model and were based on the failure description from the first step.

5. Linking of causally determined failure chains with failure analysis methods for the identification of the failure cause.

The first step in the approach is to define the problem in relation to the system, which is described based on its elements and relations between elements. Next, the system boundary has to be defined in order to delimit the system from its environment. In the third step a system model has to be created. Therefore, a standardized model will be used by being basis of data, information and knowledge. The basic model for the system modeling is the Demand Compliant Design (DeCoDe). This means that system elements and interrelations of the system are assigned to the four sights which are requirements, functions, processes and components. Furthermore, the interaction of the system elements within the whole system will be considered [32]. For the linking between system elements (requirements, functions, processes and components) a matrix was used, also called DeCoDe - main matrix (cf. Fig. 1). The four sights, which are opposed to each other, are to be linked systematically and purposefully. Each matrix represents the dependence, interdependency and interaction of the system elements. 


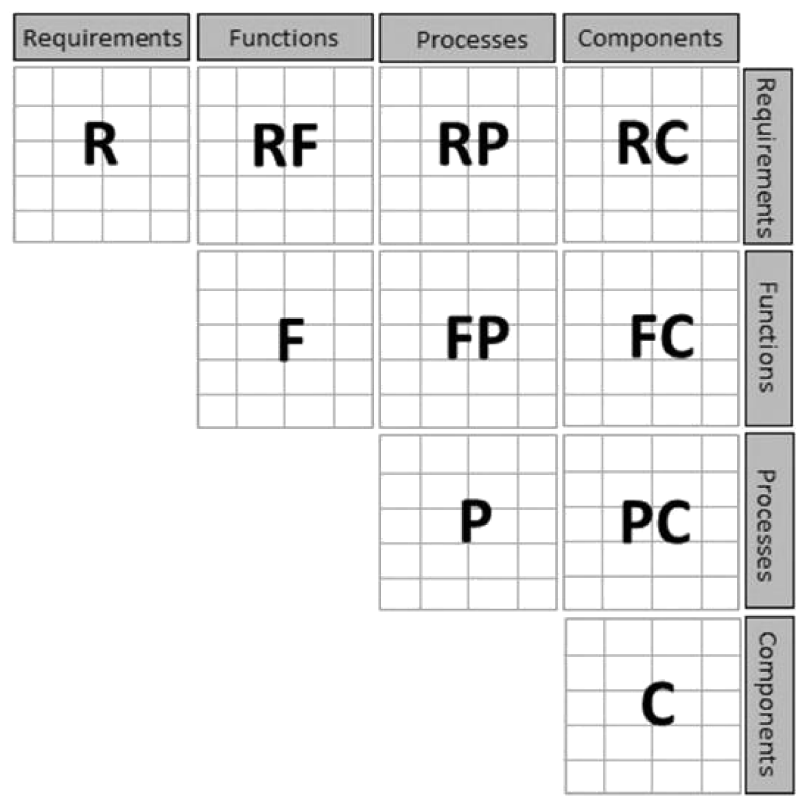

Fig. 1. DeCoDe-main matrix as tool for the implementation of DeCoDe [33].

It has already been proven that the reproduction of potential failures from element to element can be identified by using the DeCoDe model [34]. Nevertheless, causally determined failure chains were not used before, although they already exist in the system model. They cannot be identified and isolated. In the fourth step, complex failure chains, generated from the system model, will be isolated and analyzed. The "failure description" from step one delivers input for the analysis of complex causally determined failure chains. Due to the growing complexity of technical systems, the failure chains are expected to be arbitrarily complex [21]. In that case determinated failure chains include more than a one-system level and networks of different kinds of system elements (cf. Fig. 2).

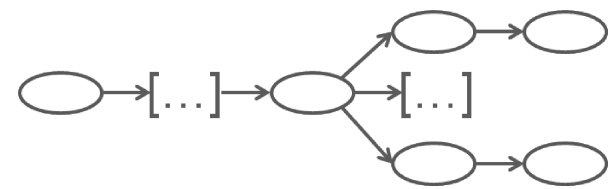

Fig. 2. Length and network of complex causally determined failure chains [17].

As seen above, the failure analysis methods that have been found in the scientific and technical literature are divided into deductive and inductive methods. Assuming that a failure could be a cause from other failures or effects from another failure in the same time [35], a failure can be considered as a point of view from that could be analysed in two directions (cause or effect). Based on the assumption from the complex relationships of cause and effect as a causal chain, a failure can be seen as intermediate elements (link) in the chain (cf. Fig. 2).

Borgeest and VDA $[18,22]$ defined regarding to the FMEA, that it is a subjective opinion to diagnose on which link in the chain is mainly focused. Independent of the initial system failure, the new approach of complex causality determined failure chains must be applicable inductive as well as deductive for a complete and integral analysis (cf. Fig. 3).

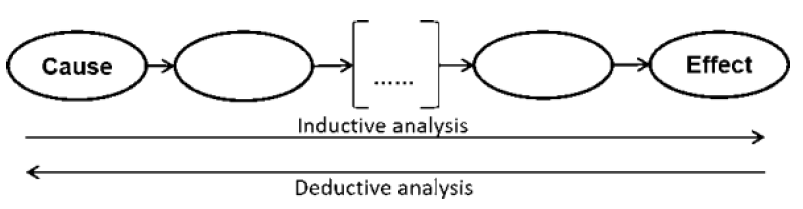

Fig. 3. Inductive and deductive analysis [17].

For that reason, it is necessary to integrate the DeCoDe system model in the new approach to analyze causality determined failure chains. Figure 4 shows the integration of the decode system model in the new approach and sums up the step from one to four.

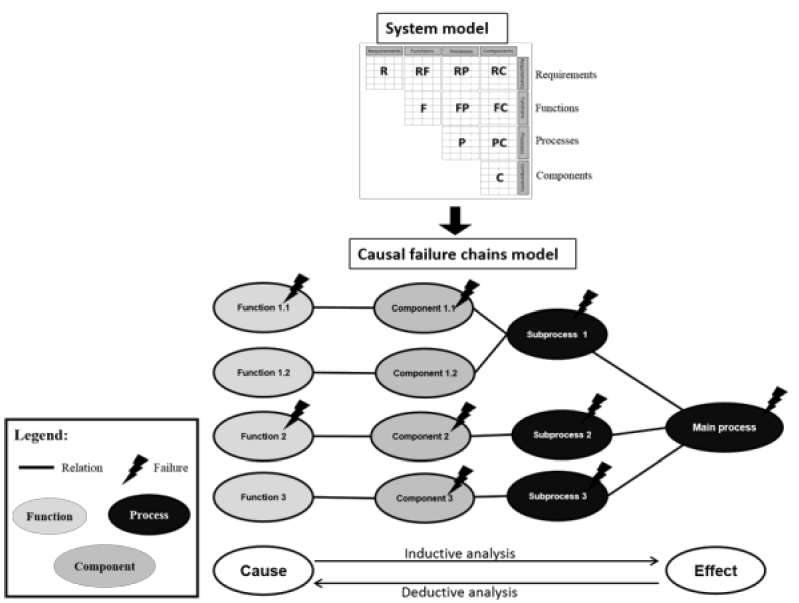

Fig. 4. Integration of the decode system model in the new approach.

In Fig. 4, a theoretical example of identified and isolated failure chains, which was taken from the system model, can be seen. The Fig. 4 shows, how failures can be tracked over various levels within different kinds of element types. Furthermore, the relation between system elements and hierarchy of the system elements gives a better description of the potential for failures and can be use for more detailed failure analysis.

In the last step, the linking of causally determined failure chains with failure analysis methods for the identification of the failure cause will be linked with the most important failure analysis methods by using the DeCoDe system model. The information and knowledge from the system model provides input in 
the form of isolated and causally determined failure chains for the application of the methods, for example FTA (cf. Fig. 5).

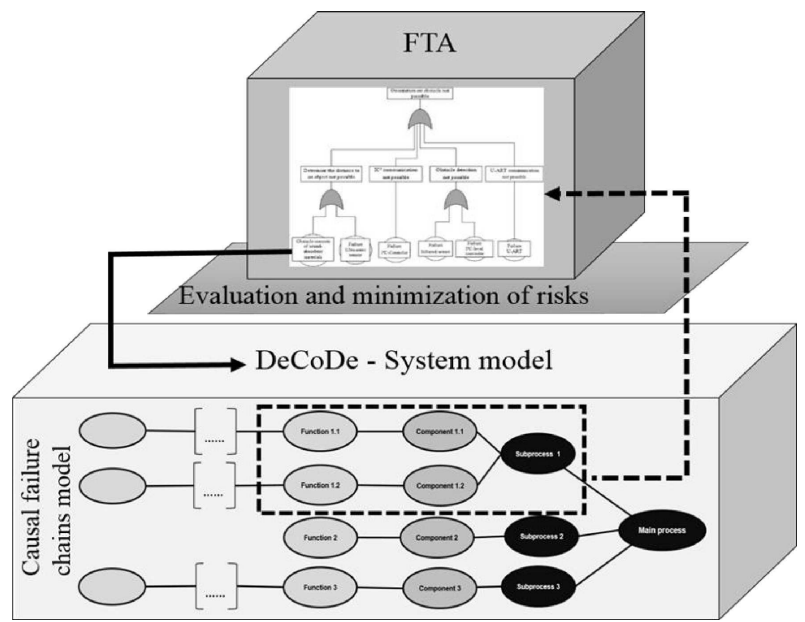

Fig. 5. Combination of failure analysis methods with decode system model.

The results from the combination of failure analysis methods with DeCoDe is transferred back into the system model (cf. Fig. 5). This way, the system model is continuously updated and provides an up to date information pool for the next method. For a better understanding, the approach of causally determined failure chains will be shown by using an example in following section.

\section{Practical application of complex causally determined failure chains by the example of an autonomic robot}

The example is about an autonomic robot, developed by (c)FH Südwestfalen in Soest. The main functions of the robot are the autonomic exploration of buildings, terrains and the autonomous generation of maps. The five steps for developing complex causally determined failure chains that have been shown in the previous section will be applied by using the autonomic robot as an example.

\section{1) Definition of the problem and the system}

The following problem occurs in the test phase: "Autonomic robot hits obstacles". A correlation is supposed to be between this failure and the sensoric of the autonomic robot. The sensoric from the autonomic robot must be able to gather its surrounding and detect obstacles. These requirements are fulfilled by infrared sensors, which have the function "enables obstacle detection", or an ultrasonic sensor with the function "determination of distances to objects". The measured values of the integrated sensors must be gathered and processed by a microcontroller. This failure will be analyzed with the help of DeCoDe system model and causally determined failure chains. It is expected that the failure occurs in the autonomic roboter, for that reason the system is defined as an autonomic roboter (cf. Fig. 6).

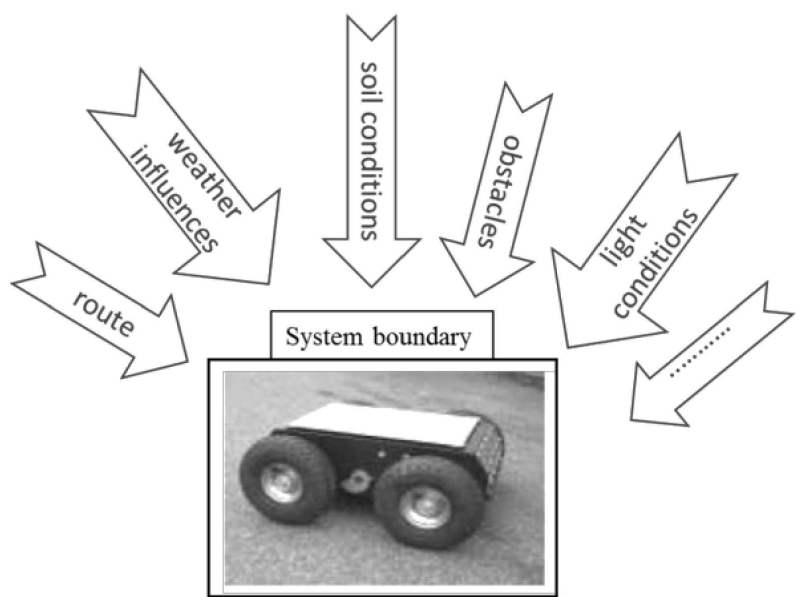

Fig. 6. Definition of the autonomic robot system and system boundary.

\section{2) Definition of the system boundary}

Before modelling the system, it is necessary that the system boundary has already been defined [32]. Surrounding factors like obstacles, weather influences, soil or light conditions are not considered at the beginning of the modelling. However, these influences over the system will be considered in the last step of the approach.

3) Definition of the purpose reagarding modelling the system

The purpose reagarding modelling the system is to generate a system model, based on failure chains by identifying and analysing. In order to do that, the DeCoDe system model has been chosen, as already mentioned in section above. In this case, it is just necessary to model three views of the system (functions, processes and components) because the autonomic robot system already exists and the requirements will not be considered at that certain time of modelling. Due to the fact that the failure only occurs in a movement process, the modelling begins with the processes of the autonomic robot. In addition, for an integral analysis, components, which are used by the processes and functions have been realized by components, must also be taken into account.

First step of the modelling is to take information and knowledge about the autonomic robot and enter this in a structured way in the DeCoDe - main 
matrix (cf. Fig. 7). The DeCoDe - main matrix consists of design structure matrices (DSM) and domain mapping matrices (DMM). Whereas DSM depict interactions between elements of the same sight (e.g. hierarchy of the components), DMM include two sights (e.g. components realize functions). Furthermore, all sights oft the systems and all the interactions between elements can be seen in a multi domain matrix (MDM) [37]. The system model was created and stored by using Loomeo ${ }^{\circledR}$ a software-tool suitable for complexity management and systems engineering [36]. It basically stores information in matrices and may display it in graphs, as shown below.
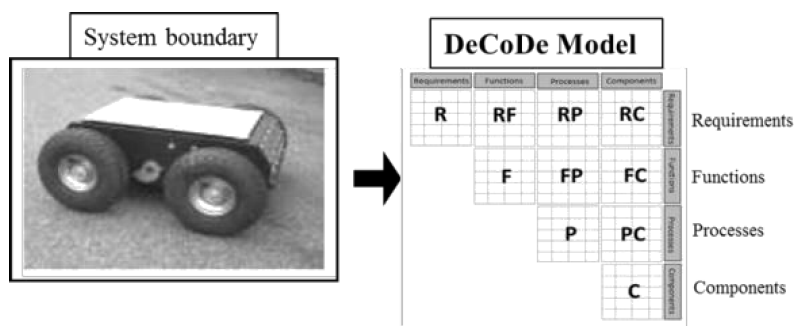

Fig. 7. DeCoDe applied to autonomic robot system (Source: ${ }^{(C)}$ FH Südwestfalen).

\section{Processes}

The processes of the system are modeled first in order to focus only on the relevant components. The main process (level 0) is subdivided in several first level processes, which are all part of the main process. Thus, there is a hierarchical relation within the process sight. The first level processes from the autonomous robot are "1. Movement", "2. Configuration", "3. Communication" and " 4 . Time control". The first level describes use cases and operating conditions that require an adapted system performance. How these use cases are conducted is specified in the second system level, which goes more into detail (cf. Fig. 8).

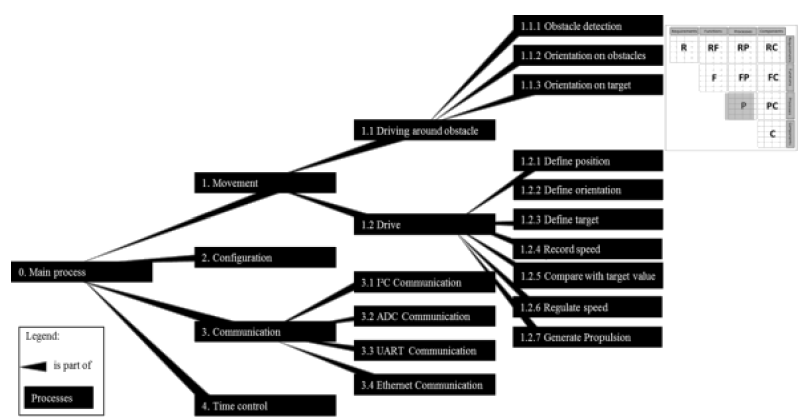

Fig. 8. Process hierarchy; relation means "is part of".

The DeCoDe minimatrix (top right in the picture) shows the viewing angle whereby the whole system is currently being analyzed.

\section{Components}

Similar to the processes, the component sight is structured hierarchically. Figure 9 clearly points out, that the physical structure of the system "autonomous robot" consists of four level. Both main components interact with each other, especially in terms of information and energy transfer.

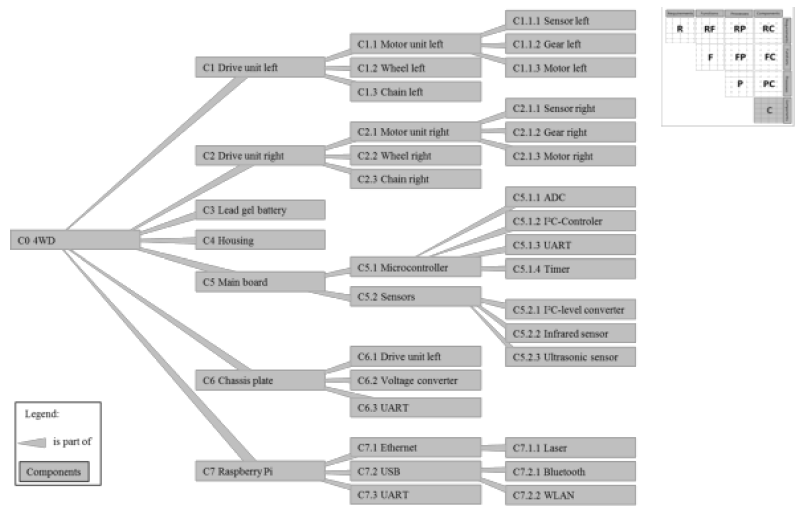

Fig. 9. Component hierarchy; relation means "is part of".

\section{Domain mapping matrices (DMM)}

For displaying relations between elements of more than one sight (for example processes and components), a domain mapping matrices (DMM) is needed. In Fig. 10 is shown a DMM that links elements of two sights. It can be chosen freely, which of the stored elements and relations should be displayed. In Fig. 10 the hierarchies within the process sight and the component sight are depicted, to give a better understanding of the structure where the different elements belong to.

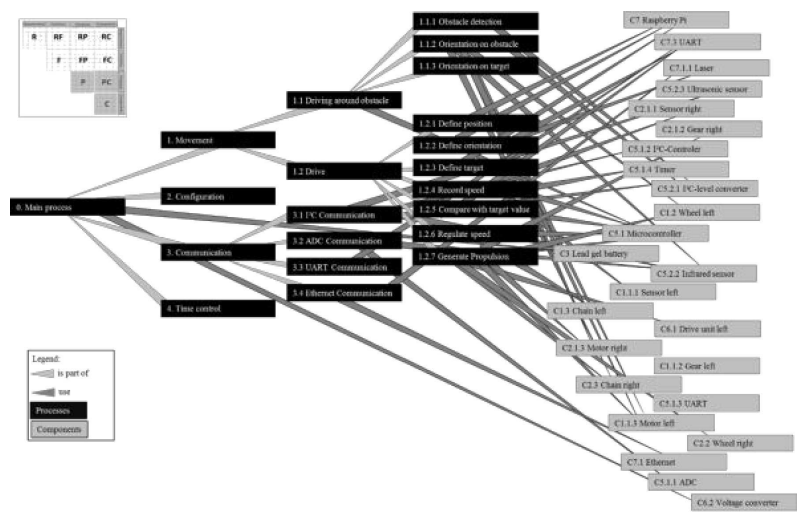

Fig. 10. Domain mapping matrices as graph "Components are used by the processes".

The graphs give information about the structure hierarchy of the processes and which components are used by the processes, so that the processes can be realized. If there is a specific problem concerning one element, for example one process, all processes that 
are not directly relevant for this problem can be faded out. The third display of the system by using the software-tool Loomeo ${ }^{\circledR}$ is the multi domain matrix (MDM). This matrix of the system makes it possible to visualize three different views of the system (processes, components and functions) at the same time. With this option cause and effect of failures in the system can be shown. Moreover, even different kinds of element types are involved.

\section{Multi domain matrix (MDM)}

Three views of the system (processes, components and functions) and their cross-linkings are shown graphically in Fig. 11 by using MDM. The picture shows that components are used by the processes and realize functions.

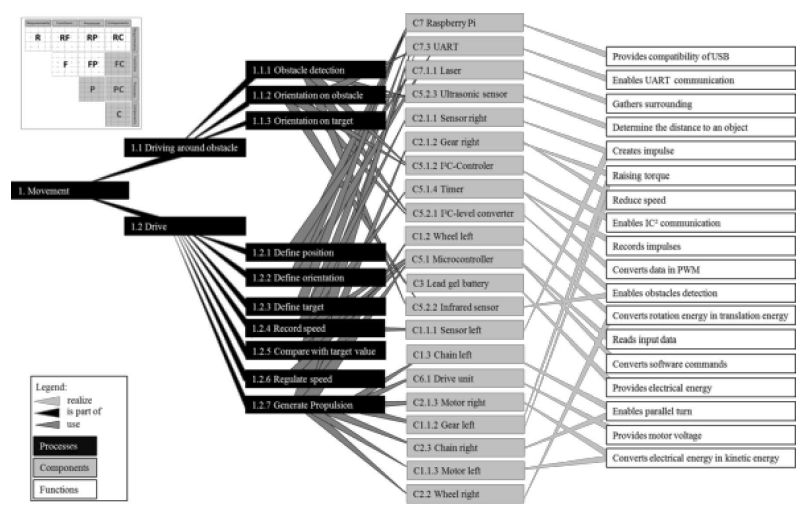

Fig. 11. Multi domain matrix as graph: Components are used by the processes and components realize functions.

The graphic in Fig. 11 represents the basis for the investigation regarding the isolation and analysis of complex failure chains, which will be explained in the next step.

4) Isolation and analysis of complex failure chains generated from the system model and based on the failure description from the first step

The analysis starts in the processes "1.1 Driving around obstacle", it is obvious that (a) failure(s) occur in this process. The software Loomeoß makes it possible to see a graphic representation of all DeCoDe matrices in the MDM (cf. Fig. 11). In addition, it offers the option to use the so called "focus" function. When a single element has been selected by using focus function, all the other system elements, which are not linked with the selected element, will be hidden. Thus, a purposeful analysis regarding cause and effect can be realised (cf. Fig. 12).

So the "focus" option shows a small section of the whole system and can be used to identify interdependency and interaction of a selected elements, in this way complexity will be reduced. With this option cause and effect of failure chains can be identified including different level of the system or different kinds of element types (functions, processes or components). In addition, failure chains can be isolated and visualised as it is shown in Fig. 13. In this figure you can see a potential source of failures (causes), which have negative effects on the process "1.1 Driving around obstacle"(system level 2) and part of in the main process "1. Movement" (system level 1). The potential source failures are additionally marked with a lightning. Furthermore, the direction of the analysis is from effect to cause (deductive analysis).

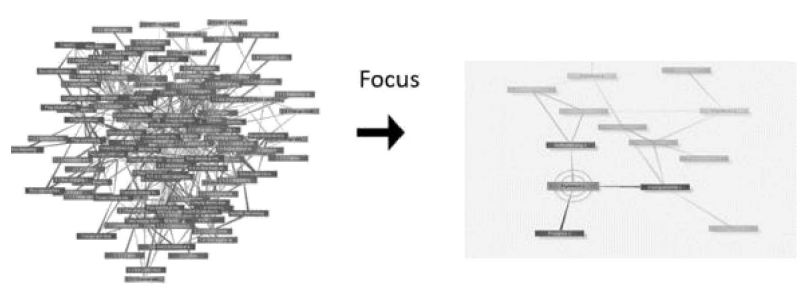

Fig. 12. "Focus" option in the Sotware Loomeo ${ }^{\circledR}$.

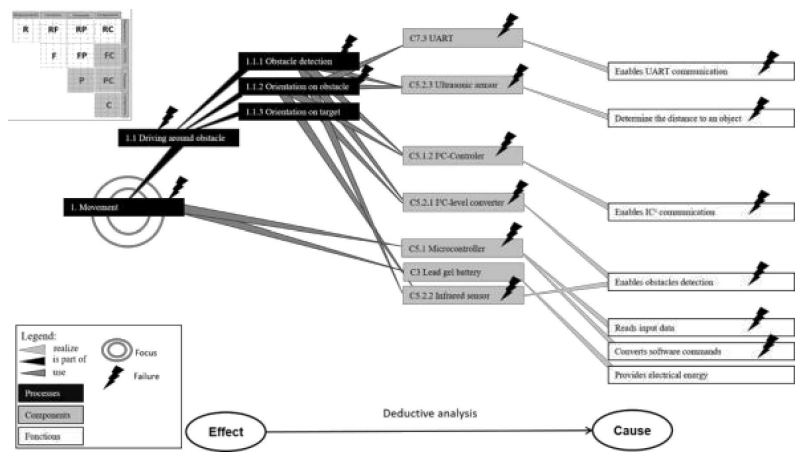

Fig. 13. Analysis of complex causally determined failure chains in the process "1.1 Driving around obstacle" using option "focus".

The FTA has been selected exemplarily as an analysis method to link it with the DeCoDe system model. The information and knowledge from Fig. 13 provides input for the application of the FTA. Therefore, the determined functions in Fig. 13 will be negated, for example the function "Enable obstacles detection" became "Not enable obstacles detection". Moreover, because of the fact that statistical data is not available, a qualitative FTA will be executed.

5) Linking of causally determined failure chains with failure analysis methods for the identification of the failure cause

The basic idea of the FTA is to describe the combination of events that lead to a top event by using Boolean gates (cf. Table 2). The FTA is graphically setup top-down from the final consequence (effect) - 
a systems or subsystems breakdown - over different Boolean gates to basic events (causes) [23, 38].

Table 2

Fault Tree Symbols [23].

\begin{tabular}{l|l}
\hline$\square$ & AND-gate \\
\hline$\square$ & OR-gate \\
\hline 0 & Basic - event \\
\hline$\square$ & Top - event or event \\
\hline
\end{tabular}

A quantitative FTA depicts a system in the so called negative logic, so the question the FTA answers is: "Which components must fail to cause a breakdown?" In Fig. 14 a FTA will be executed exemplary. For this purpose, as Pahl/ Beitz [12] has recommended, first it is necessary to negate the functions from Fig. 13. The construction of FTA is based on the information regarding possible sources of failures from Fig. 13. The FTA starts by the Top-event "driving around obstacle not possible" and it ends on the failure of the components (cf. Fig. 14).

The result of using the FTA is a new component: "Obstacle, which contains soundabsorbent material". The element "obstacle" has a strong influence on the function "Determine the distance to an object" which has been fulfilled by using the component "ultrasonic sensor". For example, the ultrasonic sensor cannot exactly determine the distance, because the ultrasonic signals are absorbed partially from the soundabsorbens material of the obstacle. Even if the infrared sensor detects the obstacle, the obstacle avoidance manoeuvre cannot be realized, because the microcontroller provides incorrect data from the ultrasonic. This potential failure was not considered before it has been analyzed with the FTA. This "new" knowledge has been generated by using the FTA and will be integrated in system model like in the approach from Fig. 5. A new requirement can be realized for the DeCoDe system model: "Obstacle should not contain soundabsorbent material".

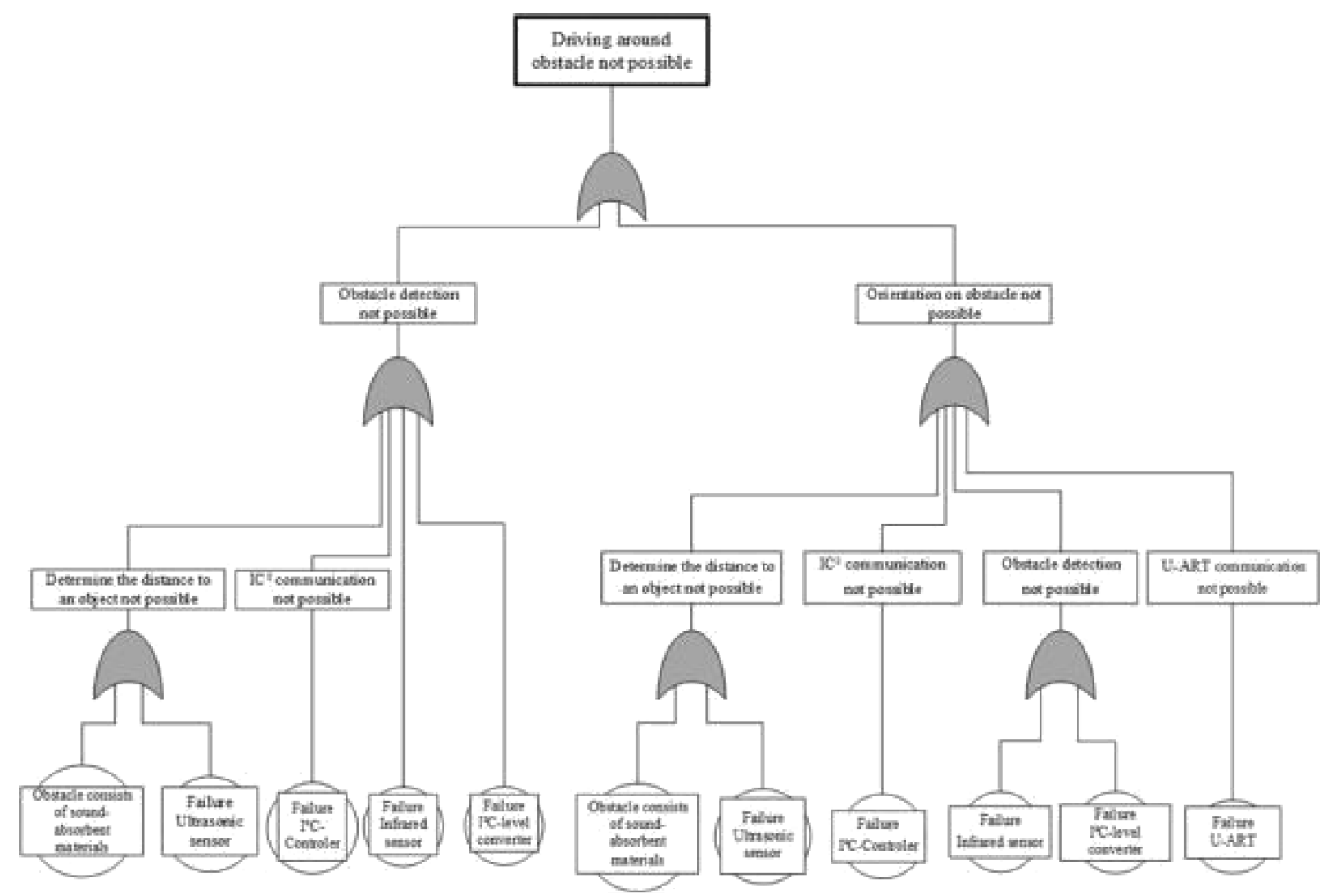

Fig. 14. FTA based on causally determined failure chains. 


\section{Conclusion}

The purpose of the paper is to present a new approach that creats a common understanding of systems and identifies failure chains and analyze them over several system level and elements.

In section two of the paper requirements have been defined which the model-based approach has to fulfill. After that in the following section it has been evaluated, if the new approach, that was presented in section 3 and carried out in section 4, fulfills those requirements:

- The failure analysis is based on an integral system model

Because of its four sights (requirements, functions, processes and components), structural overview and systematic link between the sights, the DeCoDe system model gives an integral and multidimensional overview of the system. In addition, DeCoDe enables a common language for wide range of engineering disciplines and increases the intern understanding about the whole system.

- With the help of failure chains it has to be possible to show cause and effect in a system, even if different level of a system or different kinds of element types are involved

In the above mentioned example has been shown, how failure chains with cause and effect have been isolated and visualisated by using the option "focus" of the software Loomeo ${ }^{\circledR}$. The potential failure chains from the example included different level of the system and system elements like functions, processes and components (cf. Fig. 13).

- It has to be possible to link the system model with failure analysis methods

In the last section the DeCoDe system model was linked with the FTA method. Information and knowledge from the system model provides input for the application of the FTA. Furthermore, new knowledge about the system has been integrated in DeCoDe system model accordance with the approach from Fig. 5. This procedure guarantees a continual transfer of knowledge between system model and failure analysis methods to increase reliability, quality and safety of products.

Finally, it is to mention that failure chains in the example above were not calculated, because data have not been available yet.

So, in order to check if the model based approach for complex failure chains can handle not only qualitative but quantitative analysis, further research has to be carried out. However, the software offers functions that are necessary to weight relations between elements, so that a quantitative analysis by using the software could be possible to realize. Furthermore, it is to research, if other failure analysis methods can be combined with the complex causally determined failure chains.

\section{References}

[1] Pfeifer T., Qualitätsmanagement in der Produktentwicklung, [in:] Pfeifer T., Schmitt R. (Hrsg.): Masing Handbuch Qualitätsmanagement, 6, überarbeitete Auflage, Hanser Verlag, München, 2014.

[2] Mamrot M., Entwicklung eines Ansatzes zur modellbasierten Felddatenrückführung in die Produktentwicklung, [in:] Winzer P. (Hrsg.): Berichte zum Generic-Management, Band: 2014, 1, Shaker, Aachen, 2014.

[3] Stark J., Global Product - Strategy, Product Lifecycle Management and the Billtion Customer Question, Springer, ISBN 978-84628-914-9, 2007.

[4] Pucken T., Niehues P., Systematische Risikoprävention im Einkauf braucht QM. Einkauf und QM gegen Beschaffungsrisiken, [in:] QZ Qualität und Zuverlässigkeit (01), 2014.

[5] Meyer C.-M., Integration des Komplexitätsmanagements in den strategischen Führungsprozess der Logistik, Haupt Verlag, Bern, 2007.

[6] VDI-Norm 2206, 2004: Entwicklungsmethodik für mechatronische Systeme.

[7] Heinz Nixdorf Institut: Systems Engineering in der industriellen Praxis. Studie in Zusammenarbeit mit dem Fraunhofer-Institut für Produktionstechnologie IPT in Paderborn sowie der UNITY AG in Bühren, 2013.

[8] Winzer P., Generic Systems Engineering - Ein methodischer Ansatz zur Komplexitätsbewätigung, Springer-Verlag Berlin Heidelberg, 2013.

[9] Haberfellner R., Fricke E., de Weck O., Vössner S., Systems Engineering - Grundlagen und Anwendungen Orell Füssli Verlag Zürich, 2012, ISBN 978-3280-04068-3.

[10] DIN EN ISO 9000, Qualitätsmanagementsysteme Grundlagen und Begriffe, 2005.

[11] Internationale Norm ISO 26262, Road vehicles Functional Safety, 2011.

[12] Pahl G., Beitz W., Feldhusen J., Grote K.H., Engineering design. A systematic approach, 3. Aufl. London: Springer, 2007.

[13] Vesely W., Fault Tree Handbook with Aerospace Applications, Prepared for NASA Office of Safety and Mission Assurance, NASA, 2002. 
[14] Kaiser B., Liggesmeyer P., Mäckel O., A New Component Concept for Fault Trees, [in:] Lindsay P., Cant T. (Hrsg.): Proceedings Conferences in Research and Practice in Information Technology, 2004.

[15] Meyna A., Pauli B., Taschenbuch der Zuverlässigkeitstechnik. Quantitative Bewertungsverfahren, 2. Aufl., Praxisreihe Qualitätswissen, Hanser, München, Wien, 2010.

[16] Gausemeier J. (Hrsg.), Frühzeitige Zuverlässigkeitsanalyse mechatronischer Systeme, Hanser, München, Wien, 2010.

[17] Willing M., Winzer P., Fehler vermeiden heißt Fehler verstehen - Anforderungen an eine neue Methodik, [in:] Bracke S., Mamrot M., Winzer P. (Hrsg.): Qualitätsmethoden im Diskurs zwischen Wissenschaft und Praxis, Bericht zur GQWJahrestagung 2015 in Wuppertal, Band: 2015, 17, Reihe: Berichte zum Qualitätsmanagement, ISBN 978-3-8440-3351-9, Januar 2015.

[18] Verband der Automobilindustrie (VDA): Sicherung der Qualität in der Prozesslandschaft. Allgemeines, Risikoanalysen, Methoden, Vorgehensmodelle, Oberursel (Qualitätsmanagement in der Automobilindustrie, 4), 2013.

[19] Neghab A., An Integrated Approach for RiskAssessment Analysis in a Manufacturing Process Using FMEA and DES, Published 2011 in IEEE.

[20] Liggesmeyer P., Trapp M., Safety. Herausforderungen und Lösungsansätze, [in:] Bauernhansl T., ten Hompel M., Vogel-Heuser B. (Hrsg.): Industrie 4.0 in der Produktion, Automatisierung und Logistik. Springer Vieweg Verlag, Wiesbaden, 2014.

[21] Stephan M., Fehlersensitive Produktgestaltung in integrierten Systemarchitekturen, IPK (Berichte aus dem Produktionstechnischen Zentrum Berlin), Berlin, 1996.

[22] Boorgest K., Elektronik in der Fahrzeugtechnik, Vieweg, Wiesbaden, 2008.

[23] Norm DIN EN 61025, August 2007: Fehlzustandsbaumanalyse (IEC 61025:2006); Deutsche Fassung EN 61025:2007.

[24] Gäde M., Schönemann M., Türck E., Richter T., Herrmann C., Spengler T., Vietor T., Synergien in der ko-operativen Produktentstehung, [in:] Zeitschrift für wirtschaft-lichen Fabrikbetrieb, (12), 2013.

[25] Riekhof F., Winzer P., Wörner L., Kulig S., Funktionsorientierte Auslegung eines Linearantriebs, [in:] 11. Fachtagung zu dem Entwurf komplexer Automatisierungssysteme (EKA), Magdeburg, 2012.

[26] Modarres M., Functional Modelling of Complex Systems Using a GTST-MPLD Framework, [in:]
Modarres M., Poucet A. (Hrsg.): Proceeding of the first international workshop on Functional modeling of complex technical systems, Ispra, Italy, May 12-14, 1993, University of Maryland, Maryland, 1996.

[27] Adler R., Domis D., Höfig K., Kemmann S., Kuhn T., Schwinn J.P., Trapp M., Integration of Component Fault Trees into the UML, [in:] Models in Software Engineering, Springer, Berlin Heidelberg, 2011.

[28] Xiang J., Yanoo K., Maeno Y., Tadano K., Automatic Synthesis of Static Fault Trees from System Models, [in:] Fifth International Conference on Secure Software Integration and Reliability Improvement (SSIRI), IEEE, Jeju Island, Korea, 2011.

[29] Bertsche B., Göhner P., Jensen U., Schinköthe W., Wunderlich H.-J.,Zuverlässigkeit mechatronischer Systeme - Grundlagen und Bewertung in frühen Entwicklungsphasen, Springer, Berlin Heidelberg, 2009.

[30] ISO/IEC 31010, Risk management - Risk assessment techniques, 2009.

[31] Reuter A., Zuverlässigkeit zählt, [in:] Neue Energie, (12), Berlin, 2013.

[32] Winzer P., Schlund S., DeCoDe-Modell zur anforderungsgerechten Produktentwicklung, [in:] Bandow G., Holzmüller H.H (Hrsg.): Das ist gar kein Modell! Unterschiedliche Modelle und Modellierungen in Betriebswirtschaftslehre und Ingenieurwissenschaften, Gabler Verlag, Wiesbaden, 2010.

[33] Sitte J., Winzer P., Demand Compliant Design, [in:] IEEE Transactions on Systems, Man, and Cybernetics-Part A: Systems and Humans, 41, 3, 2011.

[34] Riekhof F., Willing M., Darlegung von Gestaltungsleitsätzen zur Systemmodellierung am Beispiel von K-VEC, [in:] Winzer P. (Hrsg.): Von der Produktentwicklung bis zur Business Excellence, Berichte zum Generic-Management, Band 4/2013, Shaker, Aachen, 2013.

[35] Lindemann U., Methodische Entwicklung technischer Produkte. Methoden flexibel und situationsgerecht anwenden, 3. Aufl., Springer (VDI-Buch), Berlin, Heidelberg, 2009.

[36] http://www.teseon.de/, last clicked: 21.04.2016.

[37] Lindemann U., Maurer M., Braun T., Structural Complexity Management, Springer-Verlag Berlin Heidelberg, 2009.

[38] Vincoli J., Basic Guide to System Safety, Published 2014 by John Wiley \& Sons, Inc., 2014. 